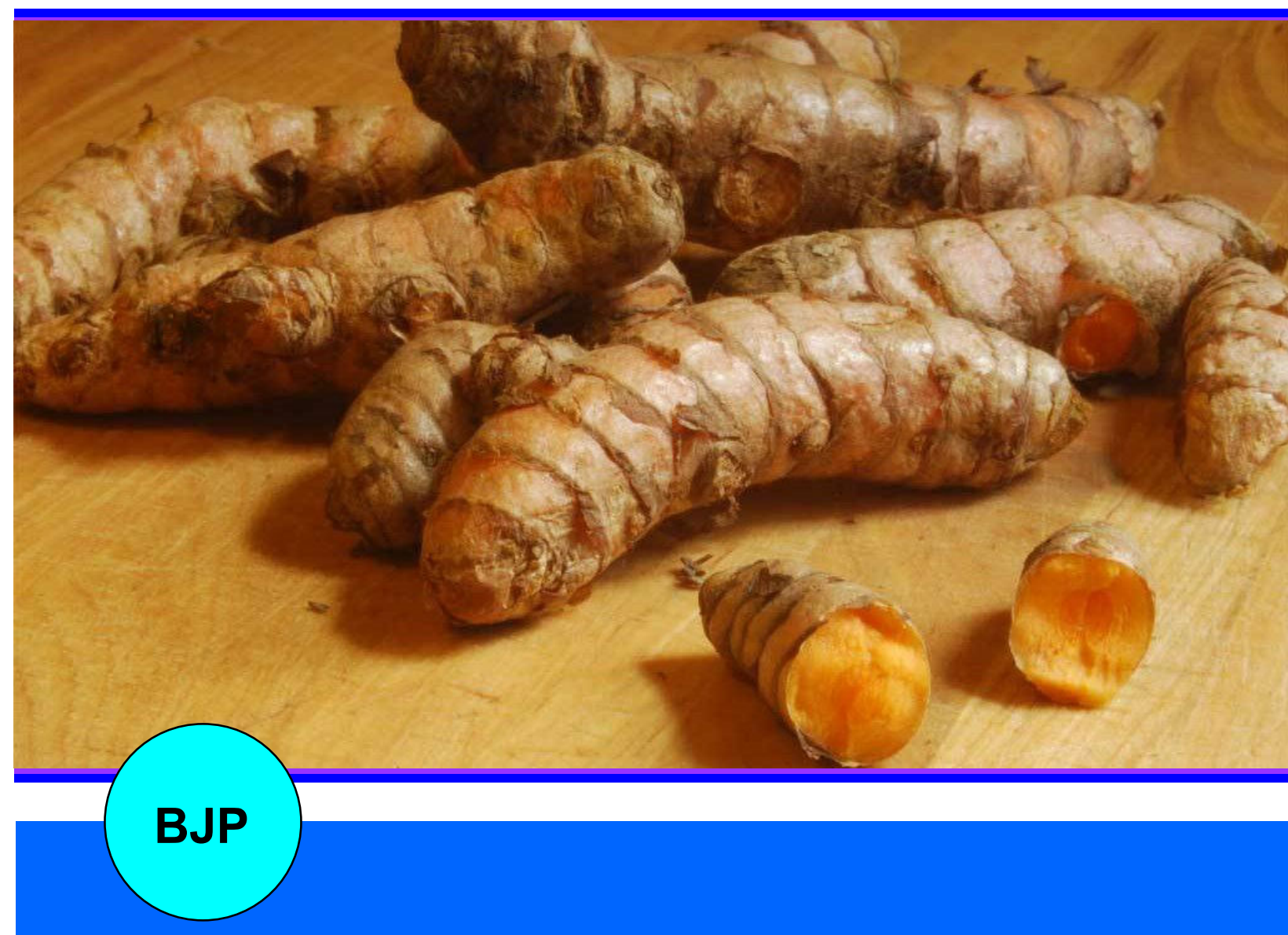

Bangladesh Journal of Pharmacology

Research Article

Occurrence of curcuminoids in Curcuma longa: A quality standardization by HPTLC 
Abstracted/indexed in Academic Search Complete, Asia Journals Online, Bangladesh Journals Online, Biological Abstracts, BIOSIS Previews, CAB Abstracts, Current Abstracts, Directory of Open Access Journals, EMBASE/Excerpta Medica, Google Scholar, HINARI (WHO), International Pharmaceutical Abstracts, Open J-gate, Science Citation Index Expanded, SCOPUS and Social Sciences Citation Index;

ISSN: $1991-0088$

\title{
Occurrence of curcuminoids in Curcuma longa: A quality standardization by HPTLC
}

\author{
M. Paramasivam¹, Md. Wasim Aktar'1, R. Poi' ${ }^{1}$ H. Banerjee' ${ }^{1}$ and A. Bandyopadhyay² \\ ${ }^{1}$ Regional Analytical Laboratory of Medicinal and Aromatic Plants, Department of Agricultural Chemicals; \\ ${ }^{2}$ Department of Spices and Plantation Crops, Bidhan Chandra Krishi Viswavidyalaya, Mohanpur 741252, Nadia, \\ West Bengal, India.
}

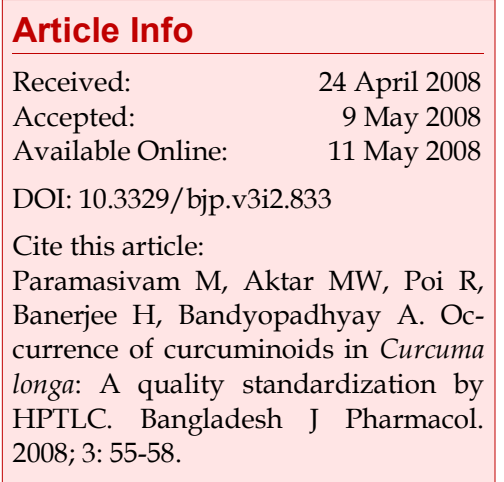

\begin{abstract}
A simple high performance thin layer chromatographic (HPTLC) method has been developed for the simultaneous determination of the pharmacologically important active curcuminoids viz. curcumin, demethoxycurcumin and bisdemethoxycurcumin in Curcuma longa L. The assay combines the separation and quantification of the analytes on silica gel $60 \mathrm{GF}_{254}$ HPTLC plates with visualization under UV and scanning at $425 \mathrm{~nm}$. Using this technique, the alkaloidal content of different parts of the title plant has been determined.
\end{abstract}

\section{Introduction}

Curcuma longa (Zingiberaceae), commonly called Haldi, is a well-known plant drug in Ayurvedic and Unani medicine (Chopra et al., 1956; Kapoor, 2001). It has been used for the treatment of various diseases and disorders particularly for urticaria, skin allergy, viral hepatitis, inflammatory conditions of joints, sore throat, and for wounds (Chattopadhyay et al., 2004).

Curcumin, demethoxycurcumin and bis-demethoxycurcumin, three major pharmacologically important curcuminoids, have been isolated from C. longa (Gupta et al., 1999) and has been shown to possess anti-oxidant, anti-inflammatory, anti-carcinogenic, anti-mutagenic, anti-fungal, anti-viral and anti-cancer activity (Chattopadhyay et al., 2004; Ahsan et al., 1999). Methods, so far available for the determination of these alkaloids, are very cumbersome and time-consuming and also not economically viable (Khurana and Ho, 1988; Taylor and McDowell, 1992; Schieffer, 2002).
Therefore it was thought worthwhile to develop a simple and high-precision HPTLC method for simultaneous analysis of curcumin, demethoxy curcumin and bis-demethoxycurcumin occurring in roots of C. longa.

\section{Materials and Methods}

\section{Plant material}

Rhizomes of C. longa were collected from the Experimental Farm for the Development of Medicinal and Aromatic Plants (BCKV, Mohanpur, India). The plant specimens were authenticated and a voucher specimen is deposited in the herbarium.

\section{Chemicals and standard alkaloids}

Reagents used were from Merck (Darmstadt, Germany). Analytical standards of curcuminoids were obtained from Ms. ChromaDex, Santa Ana, CA, USA. Solvents used in entire study were from Merck, India. 
The identities of curcumin, demethoxycurcumin and bis -demethoxycurcumin were confirmed by comparison of their spectral data with those previously reported (Govindarajan et al., 1980).

\section{Extraction of plant material for analysis}

Air dried $\left(35-50^{\circ} \mathrm{C}\right)$ rhizomes of seven germplasm of $C$. longa and market turmeric powder samples ( $1 \mathrm{~g}$ each) were ultrasonically extracted separately in $20 \mathrm{~mL}$ HPLC grade methanol for $15 \mathrm{~min}$ (3 times) and filtered through Whatman No. 42 filter paper after each extraction. Extracts were concentrated under vacuum and finally made up to $20 \mathrm{~mL}$ with HPLC grade methanol and ready for HPTLC analysis.

\section{Chromatographic conditions}

Chromatography was performed on glass-backed silica gel $60 \mathrm{GF}_{254}$ HPTLC layers $(20 \times 20$ cm, $300 \mu$ m layer thickness) prepared using a Camag (Multenz, Switzerland) TLC plate auto-coater. Methanolic solutions of samples and standard compounds curcumin, demethoxycurcumin and bis-demethoxycurcumin of known concentrations were applied to the layers as $7 \mathrm{~mm}$ wide bands positioned $15 \mathrm{~mm}$ from the bottom and $20 \mathrm{~mm}$ from the side of the plate, using a Camag Linomat 5 automated TLC applicator with the nitrogen flow providing a delivery speed of $150 \mathrm{~nL} / \mathrm{s}$ from the syringe. These parameters were kept constant throughout the analysis of samples.

\section{Detection and quantification of the alkaloids}

After sample application plates were developed in a Camag twin trough glass tank pre-saturated with the mobile phase chloroform:methanol $(48: 2, \mathrm{v} / \mathrm{v})$ for one hour. It was then poured in twin trough glass solvent development chamber well in advance to allow complete saturation which was further enhanced by keeping one filter paper along one wall of the twin trough chamber. The plate was then kept in a chamber and solvent front was allowed to develop at the height of 7 $\mathrm{cm}$ on the plate. The TLC runs were made under laboratory conditions of $25 \pm 5^{\circ} \mathrm{C}$ and $50 \%$ relative humidity. After drying, the spots were visualized under Camag UV cabinet (254 and $366 \mathrm{~nm}$ ). Quantitative analysis of the compounds was done by scanning the plates using Camag TLC scanner model 3 equipped with Wincats software (Camag) applying the following conditions: slit width $6 \times 0.45 \mathrm{~mm}$, wavelength $\left(\lambda_{\max }\right)$ $425 \mathrm{~nm}$, absorption-reflection scan mode. The identifycation of curcumin, demethoxycurcumin and bisdemethoxycurcumin in rhizomes were confirmed by superimposing the UV spectra of samples and standards within the same $R_{\mathrm{f}}$ window. In order to prepare calibration curves, stock solutions of curcumin, demethoxycurcumin and bis-demethoxycurcumin (1 $\mathrm{mg} / 5 \mathrm{~mL}$ each) were prepared and various volumes of these solutions were analyzed by HPTLC exactly as described above. Then calibration curves of peak area vs. concentration were prepared.

\section{Results and Discussion}

Different compositions of the mobile phase for HPTLC analysis were tested in order to obtain high resolution and reproducible peaks. The desired aim was achieved using chloroform:methanol $(48: 2, \mathrm{v} / \mathrm{v})$ as the mobile phase. The wavelength of $425 \mathrm{~nm}$ was found to be optimal for the highest sensitivity (Figure 1). The calibration curves for the alkaloids curcumin, demethoxycurcumin and bis-demethoxycurcumin were linear in the range 100-1,000 ng (Table I). The accuracy of the determination of the recovery rate was determined by triplicate analyses of the rhizomes spiked with three different concentrations of stock solution of curcumin, demethoxycurcumin and bis-demethoxycurcumin. The recovery rates were 97.3, 92.9 and $95.4 \%$ for curcumin, demethoxycurcumin and bis-demethoxycurcumin, respectively.

For the quantitative determination of curcumin, demethoxycurcumin and bis-demethoxycurcumin, the analyses of turmeric rhizome specimens of C. longa were repeated three times. The average content of curcumin, demethoxycurcumin and bis-demethoxycurcumin in the rhizomes are given in Table II. It is clear that three alkaloids were present in two cultivars viz. Kalimpong and PTS-43 having their maximum concentrations in the Kalimpong cultivar.

\section{Conclusion}

The HPTLC method for the simultaneous analysis of curcumin, demethoxycurcumin and bis-demethoxycurcumin from C. longa reported here is very simple, sensitive, economic and suitable for rapid screening of large number of plant samples. Moreover, this analysis can be performed without any special sample pretreatment and 15 samples can be analyzed on a single TLC laver $(20 \times 20 \mathrm{~cm})$.

\section{References}

Ahsan H, Parveen N, Khan NU, Hadi SM. Pro-oxidant, antioxidant and cleavage activities on DNA of curcumin and its derivatives demethoxycurcumin and bis-demethoxycurcumin. Chem Biol Interact. 1999; 121: 161-75. http:// dx.doi.org/10.1016/S0009-2797(99)00096-4

Chattopadhyay I, Biswas K, Bandyopadhyay U, Banerjee RK. Turmeric and curcumin: Biological actions and medicinal applications. Curr Sci. 2004; 87: 44-50. 


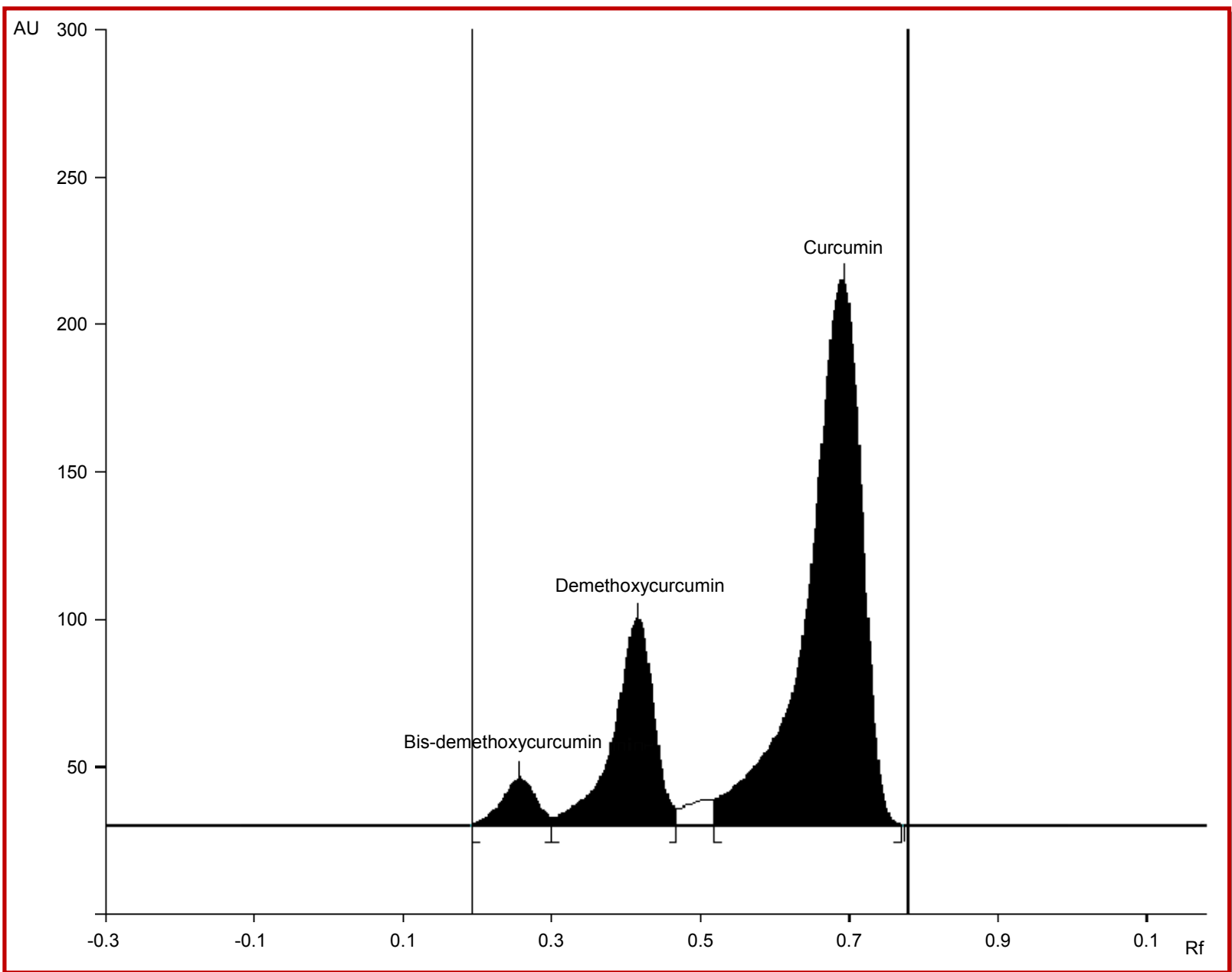

Figure 1: HPTLC chromatogram of the standard curcuminoids

\section{Table I}

$\mathbf{R}_{\mathrm{f}}$ values by HPTLC and linear regression equations for the determination of curcumin, demethoxycurcumin and bis-demethoxycurcumin

\begin{tabular}{|lccc|}
\hline Compound & $\mathrm{R}_{f}$ value & Regression equation & $r$ \\
\hline Curcumin & 0.67 & $\mathrm{Y}=47.296+0.85 \mathrm{X}$ & 0.999 \\
$\begin{array}{l}\text { Demethoxycur- } \\
\text { cumin }\end{array}$ & 0.47 & $\mathrm{Y}=186.328+0.06 \mathrm{X}$ & 0.998 \\
$\begin{array}{l}\text { Bis-demethoxy- } \\
\text { curcumin }\end{array}$ & 0.29 & $\mathrm{Y}=271.84+0.39 \mathrm{X}$ & 0.998 \\
\hline
\end{tabular}

Chopra RN, Nayar SL, Chopra IC. Glossary of Indian medicinal plants. New Delhi, CSTR, 1956, p 7.

Govindarajan VS. Turmeric: Chemistry, technology and quality. Crit Rev Food Sci Nutr. 1980; 12: 199-301.

Gupta AP, Gupta MM, Kumar S. Simultaneous determination of curcuminoids in curcuma samples using high performance thin layer chromatography. J Liq Chromatogr Related Technol. 1999; 22: 1561-69. http:// dx.doi.org/10.1081/JLC-100101751

\section{Table II}

\begin{tabular}{|c|c|c|}
\hline & Cultivar & Cultivar \\
\hline & Kalimpong & PTS-43 \\
\hline 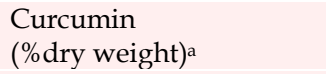 & 2.19 & 1.21 \\
\hline $\begin{array}{l}\text { Demethoxycurcumin } \\
\text { (\% dry weight) a }\end{array}$ & 1.58 & 0.72 \\
\hline $\begin{array}{l}\text { Bis-demethoxycurcumin } \\
\text { (\% dry weight) a }\end{array}$ & 1.60 & 1.22 \\
\hline
\end{tabular}

aMean values $(n=3)$

Kapoor LD. Handbook of ayurvedic medicinal plants. Boca Raton, FL, CRC Press, 2001, p 216.

Khurana A, Ho CT. High performance liquid chromatographic analysis of curcuminoids and their photo-oxidative decomposition compounds in Curcuma longa L. J Liq Chromatogr. 1988; 11: 2295-2304. http:// dx.doi.org/10.1080/01483918808067200 
Schieffer GW. Pressurized liquid extraction of curcuminoids and curcuminoid degradation products from turmeric (Curcuma longa) with subsequent HPLC assays. J Liq
Chromatogr Related Technol. 2002; 25: 3033-44. http:// dx.doi.org/10.1081/JLC-120015889

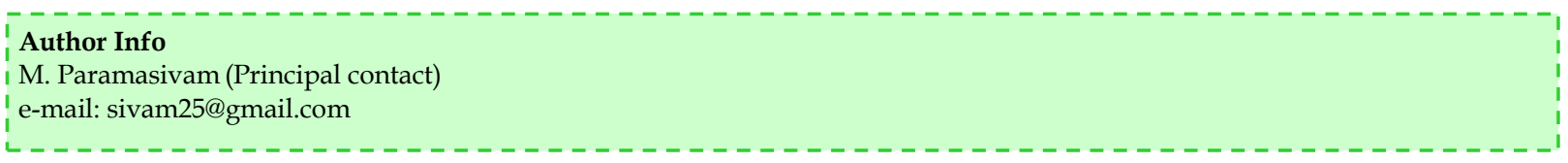

